\title{
Nachwort zur fünften Auflage
}

Auch acht Jahre nach der Erstauflage erscheint der Text dieses Bandes unverändert.

Zwar hat sich in den letzten Jahren ein weiteres Genre der Heftromanliteratur - der Horror- und Vampirroman - fest etabliert, doch käme seine Berücksichtigung in dieser neuen Auflage hauptsächlich der Vollständigkeit und dem Reiz der Belegzitate zugute, weniger dem Argumentationszusammenhang: Die Wirkung der Horrorromane ließe sich mit Hilfe der dargestellten Leserdispositionen ohne Mühe erklären.

In der Sekundärliteratur sind einige neue, zum Teil materialreiche Arbeiten über Heftromane erschienen, die hier möglichst zahlreich in die erweiterte und nun systematisch geordnete Bibliographie aufgenommen wurden, um die Studien dessen, der die 'Romane für die Unterschicht als Orientierungsgrundlage nimmt, zu erleichtern.

Die Kritik an meinem Buch hat sich auch in den letzten Jahren in den schon im Nachwort zur vierten Auflage erörterten Bahnen bewegt, so daß auch deswegen eine Überarbeitung des Textes unnötig war. Die von Wernsing/Wucherpfennig 1976 vorgebrachte These, die Heftromane erzögen die Leser aus der Unterschicht zu den Wertvorstellungen der Mittelschicht, beruht auf einer gründlichen Verkennung der von den Texten ausgelösten Identifikationsmechanismen und ihrer Wirkung; diese sind auf den vorangegangenen Seiten so ausführlich beschrieben worden, da $\beta$ sich weitere Ausführungen hierzu erübrigen.

P.N. 